\title{
Evaluating the Individual and Organizational Impact of Enterprise Content Management Systems
}

\author{
by
}

Andrea Harr ${ }^{1}$, Jann vom Brocke ${ }^{1}$, Nils Urbach

March 2019

appears in: Business Process Management Journal (2019)

1 University of Liechtenstein 


\title{
Evaluating the Individual and Organizational Impact of Enterprise Content Management Systems
}

\author{
Andrea Harr, University of Liechtenstein, email aharr@web.de \\ Jan vom Brocke, University of Liechtenstein, jan.vom.brocke@uni.li \\ Nils Urbach, University of Bayreuth \& Fraunhofer FIT, nils.urbach@uni-bayreuth.de
}

\begin{abstract}
Purpose: The overall goal of this research paper is to gain a deeper comprehension of the nature of ECM systems (ECMS) success by exploring factors that are important in the context of ECMS success, how these factors can be measured, and how they are interrelated.
\end{abstract}

Design/methodology/approach: The article develops a success model specific to the enterprise content management (ECM) domain that builds on the DeLone and McLean IS success model. The model is empirically tested by means of structural equation modeling (SEM) applying the partial least squares (PLS) approach and using data collected in an online survey.

Findings: The results show that ECMS positively affects organizational content management in terms of efficiency, collaboration, and compliance. It also provides evidence that the use of the ECMS alone does not provide impact to the organization but needs to be moderated either by the impact of the ECMS on the user or the users' satisfaction of the ECMS.

Practical implications: For practitioners, the model identifies the factors that influence the success of ECMS. Practitioners can monitor these factors as performance indicators to improve users' satisfaction with the ECMS and, thus, the success of their ECMS. Furthermore, the results can support practitioners in understanding the multiple facets of ECMS success to improve how they plan and prepare for ECM investments. 
Originality/value: The study's results contribute to theory by extending and empirically testing the D\&M IS success model in a new domain and system context. The presented research is the first to empirically validate a comprehensive ECMS success model that extends knowledge related to ECM by examining the relationship between the quality dimensions and the success measures.

Keywords: Enterprise Content Management, Enterprise Content Management Systems, Information Systems Success, Individual Impact, Organizational Impact 


\section{Introduction}

The dynamic development of new technologies like e-mail and the Internet has resulted in highly efficient ways for organizations to communicate and exchange information with customers and business partners (Gunasekaran et al., 2002). The downside of this development is that organizations now have a steeply rising amount of information and number of documents to control. A study published by IDC (Turner et al., 2014) estimated that the worldwide amount of information created and replicated double every two years and will reach 44 trillion gigabytes by 2020. Managing this large amount of information is challenging, especially considering the wide variety of types and formats in which information exists and the diverse types of devices used to access it. As a response to this challenge, several concepts for organizational information management have emerged, such as document management and (web) content management. The latest successor to these approaches is enterprise content management (ECM). ECM integrates several extant information management approaches to support organizational processes and work practices and manages content over its entire lifecycle. As such, ECM is an important facilitator for business process management (BPM) as content and high content quality usually play an important role in the management and execution of organizational processes (Frappaolo, 2008). Also processes link the different content life cycle phases with each other, and therefore business processes are the backbone of ECM (Kampffmeyer, 2006).

Technology is an important enabler of ECM. ECM systems (ECMS) can refer either to a single ECM suite that provides all functionalities required to manage an organizations content or to a single IT system or a combination of systems, such as document management systems or web content management systems (Simons and Vom Brocke, 2014). As such, ECMS are a class of information technology that supports the enterprise-wide management of content over its entire lifecycle. ECMS vendors often promise that ECMS can solve organizational information management problems and improve organizational performance by reducing time to market, enhancing knowledge sharing and collaboration, and increasing worker and process efficiency (Pullman and Gu, 2008). Because of these benefits, ECMS have received considerable attention from organizations, reflected through a steadily increasing ECMS market and prediction of revenue of $\$ 9.3$ billion in 2017 (Radicati Group, 2013). Naturally enough, organizations are interested in learning whether their considerable investments in ECMS are returning the benefits promised, but determining the return on ECMS investments is not an easy task (Allen, 2007) because the benefits of ECMS are not always easily measurable in monetary terms (Aiim, n.d.). Therefore, the benefits of investments in ECMS, as is the case with information systems (IS) in general, are rarely systematically evaluated after their implementation (Gable and Rai, 2009).

Although the field of ECM has gained increasing attention from research in the last ten years, the investigation of ECMS' impact on organizations has not. Therefore, we have only a vague understanding of what drives ECMS success or how its success (or lack thereof) can be measured. This 
research gap has also been uncovered by other researchers. Simons and Vom Brocke (2014) concluded that "the impact of ECM on individuals, groups, and organizations has rarely been investigated empirically" (p. 6), while Alalwan and Weistroffer (2012) stated that "[r]esearch is needed to address how ECM performance can be evaluated" (p. 454), Munkvold et al. (2006) found a need to evaluate "the impacts of comprehensive ECM programs" (p. 93), and Rickenberg et al. (2012) called for validation of "ECM benefits empirically and quantitatively" (p. 9). Therefore, the purpose of our study is to contribute to information systems (IS) research by developing a more precise understanding of organizational ECMS success. More specifically, our research explores what factors explain ECMS success, how they are interrelated, and how they can be measured. Thus, the goal of this study is to develop and empirically evaluate a success model that is specific to the ECM domain with a particular focus on the organizational impact of ECMS, particularly the impact of ECMS on certain objectives that have been reported in the ECM literature.

\section{Foundations}

\subsection{Enterprise Content Management}

When the ECM concept emerged at the beginning of the millennium, there was no agreement on what it covers. Smith and Mckeen (2003) noted that, "if there's one thing that all the experts agree on, it is that no one really knows exactly what ECM really is" (p. 648, citing Gilchrist, 2001). While ECM was first understood as a technological solution, during the last decade its definition has broadened to include non-technological perspectives. Now, more than a decade later, ECM can be understood as "the strategies, processes, methods, systems, and technologies that are necessary for capturing, creating, managing, using, publishing, storing, preserving, and disposing content within and between organizations" (Grahlmann et al., 2012, p. 272). As such, ECM is an approach to information management with an enterprise-wide focus and that crosses organizational boundaries by including entire supply chains (Simons and Vom Brocke, 2014). The ECM definition already suggests that ECM plays an important role in business processes. On the other side, organizational processes play an important role in ECM as the successful customization and implementation of ECMS require a deep understanding of content-related activities (Vom Brocke et al., 2011b). As such, the boundaries of the concepts are still fuzzy (Chambers, 2007).

ECMS are the technical facilitators of the management of an enterprise's content (Grahlmann et al., 2012). The ECMS market contains a plethora of vendors that offer monolithic ECM suites as well as single IS that focus on particular types of content and applications and offer various ECM capabilities. Among the core ECM components and capabilities of ECMS are document management (e.g., check-in/check-out, version control), image-processing applications (e.g., capturing, transforming and managing images of paper documents), content workflow (e.g., supporting business processes, routing of content, assigning work tasks and states), records management (e.g., long-term retention of content, ensuring legal, regulatory 
and industry compliance), web content management (e.g., administrating and controlling of web content through the use of certain management tools), and social content (e.g., document sharing, collaboration, knowledge management) (Gartner, 2014).

While research and practice have paid some attention to the reasons for organizational ECM interest and investments, we have only a vague understanding of what constitutes the success of ECM in organizations, what organizations actually gain through ECM and to what extent they realize their specific ECM objectives (e.g., compliance, enhanced collaboration) by implementing ECMS. Only little research has been conducted to investigate what dimensions influence the success of ECM and what effect ECM has on the individual or the organization. Therefore, an ECMS success model can be of value to both practitioners and researchers. For researchers, an ECMS success model can help to identify the dimensions of ECMS success and to determine the causality and relationships among these dimensions. Practitioners can benefit from an ECMS success model by using the resulting survey tool to evaluate their ECM success after implementing ECMS.

\subsection{IS Success}

The evaluation of IS success has received considerable attention in IS research (Urbach et al., 2009). This IS research stream "evaluates the effective creation, distribution, and use of information via technology" (Petter et al., 2012, p. 342), but defining the term "IS success" is not an easy task. The literature presents several definitions, but the definition of the term depends to a great extent on the stakeholder's perspective (Urbach et al., 2009). For an organization the success of IS might be based on increasing profits, whereas success for an individual employee might mean the simplification of daily tasks (Urbach et al., 2009).

To clarify the nature of IS success, DeLone and McLean (1992) carried out a literature review from which they derived a comprehensive IS success model. Other theories and models that emerged at around the same time to address the measurement of IS success included Seddon's IS success model (1997), which extends the D\&M IS success model (1992), and the technology acceptance model (Davis, 1989) and its extensions, which evaluate the technologies' level of acceptance. A decade after DeLone and McLean presented their D\&M IS success model, they extended and updated it by adding a service quality dimension that reflects the increasing role of organizations in providing support for end users and by merging two constructs that referred to the impact of IS on the individual and the organizational level into one net benefits construct (Delone and Mclean, 2003). With these two modifications, the updated D\&M IS success model comprised six interrelated constructs: information quality, system quality, service quality, (intention to) use, user satisfaction, and net benefits.

Since then, the D\&M IS success model has been discussed, modified, and applied in various IS research streams, some of which can be considered ECM-related. For example, Kulkarni et al. (2007) developed and tested a knowledge management (KM) success model based on the D\&M IS success model (2003, 
1992), and Paré et al. (2005) evaluated a success model for a picture-archiving and communication system (PACS) from multiple users' perspectives in a health-care setting. Their study showed that different user groups, such as radiologists, technologists, and clinicians, have different views concerning the factors that influence PACS success (Paré et al., 2005). Adeyinka and Mutula (2010) developed a model for evaluating WebCT course content management systems (WebCT CCMS) success, a system that manages teaching and learning by supporting the procedures of content creation, storage and retrieval, transfer, delivery and application, in an educational setting. Urbach et al. (2010) developed and evaluated a success model for employee portals, arguing that two major purposes of employee portals are the technical support of business processes and enabling collaboration among users, so they extended the D\&M IS success model to include the quality dimensions of collaboration and process quality (Urbach et al., 2010). Gable et al. (2003) developed a model for enterprise systems success using the dimensions information quality, system quality, individual impact, and organizational impact.

These ECM-related studies were all based on the D\&M IS success model $(2003,1992)$, so we can assume that the D\&M IS success model can serve as a foundation for explaining ECMS success as well. To our knowledge, no theoretical model for explaining the success of ECMS has been proposed. Although these ECM-related studies present important sub-dimensions of ECM, such as content archiving, storage, and retrieval, none of them covers the full spectrum of ECM. In addition, these models are specific to the context in which the studies were conducted (e.g., picture archiving in hospitals, content management in an educational setting) and when considering the six components of the IT systems classification as proposed by Seddon et al. (1999), they refer to the assessment of single IT applications in a single context. However, ECM is usually realized through various integrated technologies and applications that reflect multiple aspects of ECM, so a deep evaluation of the factors that drive the success of ECMS as a specific class of IT applications is needed. In addition, the extant studies cited here do not include specific ECM objectives as factors for measuring the success of ECMS on the organizational level, a criticism that is in line with the finding of two literature studies that suggested that the organizational impact of IS has received much less attention in research than has the individual impact (Petter et al., 2008, Urbach et al., 2009). Therefore, there is a need to clarify the nature of ECMS success from the organizational perspective, not just from the individual perspective.

\section{Research Model}

This section presents the development of our research model. The model builds on and extends the D\&M IS success model $(2003,1992)$. Because it has been tested and proven in many IS contexts, we kept as many of the elements of the original D\&M IS success model as possible. However, as DeLone and McLean (1992) pointed out, because IS success is a multidimensional concept, its measurement should involve measures that are suitable to the research objective and method, organizational context, and level of analysis. Therefore, we extended the D\&M IS success model with constructs specific to the ECM 
domain. In the following paragraphs, we introduce all constructs of our ECMS success model and provide rationales for our assumptions about the relationships between them.

The system quality construct refers to the characteristics of the IS that produces the information (Delone and Mclean, 1992). System quality has been shown to be an important success factor in many contexts, including ECM-related areas (Kulkarni et al., 2007, Halawi et al., 2008, Adeyinka and Mutula, 2010). Therefore, we assume that system quality is also a valid factor in measuring ECMS success, because ECMS with poor technical performance or with missing technical functionalities like search and retrieval would hinder the user's performance of daily tasks because of extra time and effort required.

Service Quality was suggested as another construct for measuring IS Success (Pitt et al., 1995, Delone and Mclean, 2003). It was argued that the development of information technology (IT) requires organizations to provide both the information products and support for the end users (Delone and Mclean, 2003). Because service quality is a construct from the D\&M IS success model (Delone and Mclean, 2003) and because ECM-related studies have shown that it is a valuable measure for assessing IS success (e.g., Adeyinka and Mutula, 2010), we include service quality in our ECMS success model.

Finally, the quality of information has received some attention in the ECM literature, and studies that have investigated ECM drivers and objectives have reported the need to improve or maintain information quality through organizational ECM initiatives (e.g., Vom Brocke et al., 2011c, Päivärinta and Munkvold, 2005). Additionally, information quality has been shown to be an effective IS success measure in many contexts, including ECM-related domains (e.g., Adeyinka and Mutula, 2010, Urbach et al., 2010). Therefore, we assume that information quality is also a valid construct in our ECMS success model.

We added the final quality dimension, process quality, to the ECMS success model after our pilot study because it (and the literature (e.g., Smith and Mckeen, 2003, Tyrväinen et al., 2006)) showed that ECMS are often expected to support and simplify organizational work processes. Our initial model did not reflect process support, so we added the fourth quality dimension of process quality, which was originally introduced by Urbach et al. (2010).

The construct use is another important factor in measuring IS success because a system that is not used cannot create value for an individual or an organization. In the context of ECMS, we believe use is an appropriate measure, whether the use is voluntary or mandatory. Therefore, we assume use to be an important indicator of ECMS success, especially because ECMS functionalities such as create or store reflect different content lifecycle phases.

Further, user satisfaction is likely to be another important success dimension because a user who is not satisfied with the ECMS is unlikely to use them. However, ECMS may not positively affect all employees, especially in the beginning. In addition, user satisfaction has been shown to be a valuable success measure in ECM-related success studies (e.g., Adeyinka and Mutula, 2010, Paré et al., 2005, 
Kulkarni et al., 2007), Therefore, we include user satisfaction as a separate construct in our ECMS success model.

It has been argued that measuring the dependent variable of IS success-often called impact or net benefits-can be done on many levels (Herbst et al., 2014b, Seddon, 1997, Delone and Mclean, 2003). In their original model, DeLone and McLean suggested assessing the impact of IS on both the individual level and the organizational level (Delone and Mclean, 1992). Subdividing the impact of IS in this way is reasonable because different entities might perceive success differently (Urbach et al., 2009). Therefore, we argue that, in the context of ECM, both the individual impact and the organizational impact of ECMS are relevant to explain ECMS success.

Unlike many other information management concepts, ECM aims to manage unstructured information on an enterprise level, so implementing ECMS implies benefits for the entire organization. Because of ECMS' wide scope, their implementation usually involves considerable financial investment, so organizations want to be able to determine the success of such projects by measuring the level of achieving the goals. We conducted a literature review to identify the organizational objectives/drivers for ECM investments and identified three major drivers: efficiency, collaboration, and compliance. These three objectives were also confirmed in Rickenberg et al.'s (2012) literature review. Appendix A shows the references that mention these ECM objectives either directly or indirectly by mentioning some of their aspects. We measure the organizational impact of ECM as the extent to which the three ECM objectives are met through using ECMS.

Organizations are always searching for new ways to reduce costs and increase efficiency (Andersen, 2007). While the impact of tools like intranets and knowledge management systems on organizational efficiency has been shown (Iverson and Burkart, 2007), ECMS' impact on organizational efficiency remains uncertain. Typical characteristics of organizational efficiency that we encountered in the context of ECM in our literature study include reducing costs (e.g., Munkvold et al., 2006, Scott et al., 2004), search times (e.g., Vom Brocke et al., 2011b), and the time and effort required for content-related activities like reporting and publishing (e.g., Scott et al., 2004, Sprehe, 2005), and improving the use of organizational content (Iverson and Burkart, 2007, Vom Brocke et al., 2011c, Smith and Mckeen, 2003). Because pure financial measures for assessing organizational efficiency (Maltz et al., 2003), are elusive and because they are also easy to manipulate (Gable et al., 2003), we focus on non-financial efficiency measures gathered from characteristics encountered in the ECM literature.

The second ECM objective identified in our literature analysis is collaboration, which plays an important role in content creation (Podean et al., 2011) and its subsequent management. Content is often created by a group of people to be shared with people across the organization. The content-creation process can be broken into various tasks that must be performed in close collaboration between internal and sometimes external stakeholders (Iverson and Burkart, 2007). Eliminating departmental content 
silos where content is created and managed in isolation is important for organizations that must comply with legal regulations (Rockley et al., 2003) and that want to improve knowledge-sharing and communication within as well as beyond organizational boundaries (Vom Brocke et al., 2011b).

The last of the three ECM-specific objectives is compliance, which has been mentioned frequently as one of the main drivers for organizations to engage in ECM (e.g., Rickenberg et al., 2012, Usman et al., 2009). Legal regulations like the Sarbanes-Oxley Act and international privacy laws make it essential for organizations to be able to maintain their transaction-related records and information (Arma International, 2013). The literature mentions compliance challenges related to the management of enterprise content from undesired content and knowledge loss (Vom Brocke et al., 2011c) to storage of content in private folders (Nordheim and Päivärinta, 2006), errors in products and services (Vom Brocke et al., 2011c), and unauthorized disclosure, modification and destruction of content (Chiu and Hung, 2005). Such content management problems can lead to inadequacies in record-keeping, which can threaten an organization's very existence (Arma International, 2013).

Table 1 gives an overview of the ECMS constructs and their meaning in the context of this study.

\begin{tabular}{|c|c|c|}
\hline Construct & Origin & Definition \\
\hline System Quality & $\begin{array}{l}\text { Delone and Mclean (1992), } \\
\text { Delone and Mclean (2003) }\end{array}$ & Users' perception of the technical performance of ECMS. \\
\hline Use & $\begin{array}{l}\text { Delone and Mclean (1992), } \\
\text { Delone and Mclean (2003) }\end{array}$ & The usage of different ECMS functionalities. \\
\hline $\begin{array}{l}\text { User } \\
\text { Satisfaction }\end{array}$ & $\begin{array}{l}\text { Delone and Mclean (1992), } \\
\text { Delone and Mclean (2003) }\end{array}$ & $\begin{array}{l}\text { Users' subjective attitudes and feelings of pleasure or } \\
\text { displeasure about ECMS. }\end{array}$ \\
\hline Service Quality & $\begin{array}{l}\text { Pitt et al. (1995), Delone and } \\
\text { Mclean (2003) }\end{array}$ & $\begin{array}{l}\text { The overall support provided to users in the context of the } \\
\text { ECMS. }\end{array}$ \\
\hline $\begin{array}{l}\text { Information } \\
\text { quality }\end{array}$ & $\begin{array}{l}\text { Delone and Mclean (1992), } \\
\text { Delone and Mclean (2003) }\end{array}$ & The quality of the information that is provided by the ECMS. \\
\hline Process Quality & Urbach et al. (2010) & $\begin{array}{l}\text { The quality of support for work processes provided through } \\
\text { the ECMS. }\end{array}$ \\
\hline $\begin{array}{l}\text { Individual } \\
\text { impact }\end{array}$ & DeLone and McLean (1992) & $\begin{array}{l}\text { The extent to which ECMS influence the users' individual } \\
\text { capabilities and effectiveness while performing their jobs. }\end{array}$ \\
\hline Efficiency & Derived from ECM Literature & The organizational content management performance. \\
\hline Collaboration & Derived from ECM Literature & $\begin{array}{l}\text { The cooperation among people concerning the creation, } \\
\text { sharing, availability, and overall management of content. }\end{array}$ \\
\hline Compliance & Derived from ECM Literature & $\begin{array}{l}\text { Acting in accordance with established laws, protocols, and } \\
\text { standards concerning the management of content. }\end{array}$ \\
\hline
\end{tabular}

In the following we outline the development of our hypotheses.

Concerning the relationship between the quality constructs and use as well as user satisfaction (e.g., Adeyinka and Mutula, 2010, Paré et al., 2005, Kulkarni et al., 2007, Delone and Mclean, 2003, Delone and Mclean, 1992), we followed the suggestions of previous research assuming a positive relationship. It is likely that a bad ECM system quality and those with missing core functionalities will not be used, and for the same reason a user will not be satisfied with the system. For the construct service quality this assumption makes sense as well. ECMS changes how people work. It is likely that, especially in the beginning but also over time, questions and problems will arise concerning correct ECMS use and work- 
practice-related changes, and only if these questions and problems are appropriately addressed will a user be able using the ECMS and experience the system in a positive way. Concerning information quality, it has to be assumed that ECMS that provide users with low-quality information products are of no benefit, so there is no need for users to use such ECMS. And if ECMS do not provide high quality information, users are unlikely to be satisfied. A positive relationship between process quality and the constructs use and user satisfaction can also be assumed in the context of ECM. ECMS are meant to support organizational work practices, but a system that fails to do so adds no value to the users' work practice, making it unlikely that a user will use the system or that he or she will be satisfied with it.

The constructs use and user satisfaction are predicted to have a positive relationship with each other (Delone and Mclean, 2003, Delone and Mclean, 1992). To be satisfied with ECMS, a user must first use a system. We can also assume that, with increasing use of ECMS, users get to know the systems and develop routines for using them for their own benefits (e.g. improving personal work performance), increasing ECMS satisfaction. A satisfied user is likely to use ECMS more often than an unsatisfied user (Delone and Mclean, 2003, Delone and Mclean, 1992). Also, in their original IS success model, DeLone and McLean (1992) predicted a positive relationship between individual impact and use and between individual impact and user satisfaction. The rational for this assumption is that a user's using ECMS or the user's satisfaction with ECMS will lead to individual benefits. In their employee portal success model, Urbach et al. (2010) predicted that process quality has a positive influence on use and on user satisfaction, which can also be assumed in the context of ECMS.

We identified all three constructs - efficiency, collaboration, and compliance-as specific goals that organizations pursue through the implementation and use of ECMS, so their realization can be seen as an organizational benefit. In their original model, Delone and Mclean (1992) hypothesized that the impact of IS on an individual's performance will eventually have some impact on the organization. This argument is reasonable because a user who benefits from using an ECMS also saves this time and effort for the organization. However, it can be assumed that ECMS use and the users' satisfaction with the ECMS not just influences the individual but at the same time the organization independent of the impact of the ECMS on the individual. While individual ECMS use might be beneficial for an organization in terms of a higher level of compliance or an increased level of efficiency, it might imply at the same time additional effort for a user's daily routines by, for example, requiring the addition of meta data to information or scanning paper documents (Herbst et al., 2014a) and as such not influencing a user's impact positively. A summary of our hypothesis for the ECMS success model is given in Table 2.

\begin{tabular}{|l|l|}
\hline \multicolumn{2}{|c|}{ Table 2. Hypothesis } \\
\hline No. & Hypothesis \\
\hline H1 & A high level of system quality is associated with a high level of ECMS use. \\
\hline H2 & A high level of system quality is associated with a high level of user satisfaction with the ECMS. \\
\hline H3 & A high level of service quality is associated with a high level of ECMS use. \\
\hline H4 & A high level of service quality is associated with a high level of user satisfaction with ECMS. \\
\hline H5 & A high level of information quality is associated with a high level of ECMS use. \\
\hline
\end{tabular}




\begin{tabular}{|l|l|}
\hline H6 & A high level of information quality is associated with a high level of user satisfaction with ECMS. \\
\hline H7 & A high level of process quality is associated with a high level of ECMS use. \\
\hline H8 & A high level of process quality is associated with a high level of user satisfaction with ECMS. \\
\hline H9 & A high level of use is associated with a high level of user satisfaction with ECMS. \\
\hline H10 & A high level of user satisfaction is associated with a high level of ECMS use. \\
\hline H11 & A high level of ECMS use is associated with a high level of users' individual impact. \\
\hline H12 & A high level of user satisfaction with ECMS is associated with a high level of individual impact. \\
\hline H13 & A high level of individual ECMS impact is associated with a high level of organizational efficiency. \\
\hline H14 & A high level of individual ECMS impact is associated with a high level of organizational collaboration. \\
\hline H15 & A high level of individual ECMS impact is associated with a high level of organizational compliance. \\
\hline H16 & A high level of ECMS use is associated with a high level of organizational efficiency. \\
\hline H17 & A high level of ECMS use is associated with a high level of organizational collaboration. \\
\hline H18 & A high level of ECMS use is associated with a high level of organizational compliance. \\
\hline H19 & A high level of user satisfaction with ECMS is associated with a high level of organizational efficiency. \\
\hline H20 & A high level of user satisfaction with ECMS is associated with a high level of organizational collaboration \\
\hline H21 & A high level of user satisfaction with ECMS is associated with a high level of organizational compliance \\
\hline
\end{tabular}

Our overall research model for evaluating the success of ECMS, including the hypotheses to be tested, is shown in Figure 1.

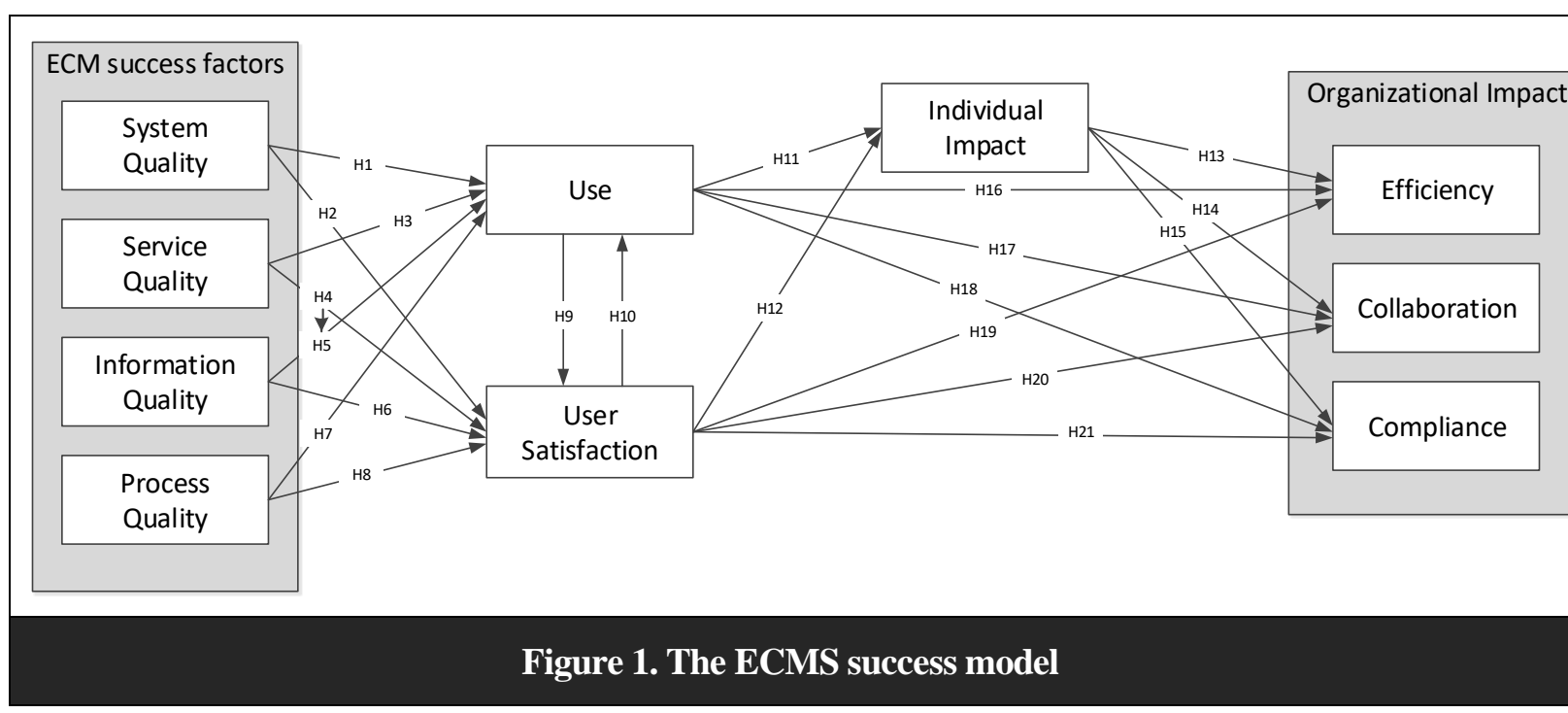

\section{Research Method}

\subsection{Instrument Development}

We followed the recommendations of DeLone and McLean (2003) and other researchers to ensure validity by relying on tested and proven measures, when they were available, to conceptualize the constructs in our model. We adopted items from previous studies and adjusted them to the ECM context and added new items if not all aspects of the domain were covered by existing ones. We identified no appropriate set of items for the new constructs efficiency, compliance, and collaboration, so we developed new items based on factors identified in the ECM literature. We engaged in a scaledevelopment process proposed by Recker and Rosemann (2010) to develop and test the ECMS success measures. Our activities included expert interviews, a card-sorting and item-ranking approach (Moore and Benbasat, 1991), as well as a pilot study with sixty ECMS users. Based on the results of these steps, 
we defined our final survey instrument. Table 3 presents the final set of items that we used in our study.

\begin{tabular}{|c|c|c|}
\hline Construct & Items & References \\
\hline $\begin{array}{l}\text { Information } \\
\text { Quality }\end{array}$ & $\begin{array}{l}\text { Relevancy, usefulness, reliability, } \\
\text { timeliness, accuracy }\end{array}$ & $\begin{array}{l}\text { Items adapted from Bailey and Pearson (1983), Urbach } \\
\text { et al. (2010), Wang et al. (2007) }\end{array}$ \\
\hline $\begin{array}{l}\text { System } \\
\text { Quality }\end{array}$ & $\begin{array}{l}\text { Ease of navigation, ease of use, user } \\
\text { friendliness, ease of information } \\
\text { access, retrieval functionalities }\end{array}$ & $\begin{array}{l}\text { Items adapted from Bailey and Pearson (1983), Urbach et } \\
\text { al. (2010), Wang et al. (2007); new item derived from } \\
\text { Grahlmann et al. (2012) }\end{array}$ \\
\hline $\begin{array}{l}\text { Service } \\
\text { Quality }\end{array}$ & $\begin{array}{l}\text { Responsiveness, reliability, } \\
\text { assurance, availability, quality of } \\
\text { training }\end{array}$ & $\begin{array}{l}\text { Items adapted from Urbach et al. (2010), Wang et al. } \\
\text { (2007); and Pitt et al. (1995) }\end{array}$ \\
\hline $\begin{array}{l}\text { Process } \\
\text { Quality }\end{array}$ & $\begin{array}{l}\text { Traceability, accuracy, ease of } \\
\text { initiation, reliability, completeness }\end{array}$ & Items adapted from Urbach et al. (2010) \\
\hline Use & $\begin{array}{l}\text { Extent of using typical functions, } \\
\text { frequency of using the ECMS }\end{array}$ & Items adapted from Urbach et al. (2010); Iivari (2005) \\
\hline $\begin{array}{l}\text { User } \\
\text { Satisfaction }\end{array}$ & $\begin{array}{l}\text { User expectations, effectiveness, } \\
\text { efficiency, overall satisfaction, } \\
\text { pleasure of use }\end{array}$ & $\begin{array}{l}\text { Items adapted from Lin (2007), Urbach et al. (2010), and } \\
\text { Wang et al. (2007) }\end{array}$ \\
\hline $\begin{array}{l}\text { Individual } \\
\text { Impact }\end{array}$ & $\begin{array}{l}\text { Job efficiency, job effectiveness, job } \\
\text { performance, task performance, } \\
\text { productivity }\end{array}$ & Items adapted from Urbach et al. (2010) \\
\hline Efficiency & $\begin{array}{l}\text { Efficient reuse, efficient use, faster } \\
\text { publishing, reduced search time }\end{array}$ & $\begin{array}{l}\text { New items derived from Dilnutt (2006), Päivärinta and } \\
\text { Munkvold (2005), Scott et al. (2004), Smith and Mckeen } \\
\text { (2003), Munkvold et al. (2006), Vom Brocke et al. } \\
\text { (2011c), and Iverson and Burkart (2007) }\end{array}$ \\
\hline $\begin{array}{l}\text { Collaboratio } \\
\mathrm{n}\end{array}$ & $\begin{array}{l}\text { Comfort, knowledge sharing, joint } \\
\text { content creation, resolving content } \\
\text { silos }\end{array}$ & $\begin{array}{l}\text { New items derived from Munkvold et al. (2006), Podean } \\
\text { et al. (2011), Rockley et al. (2003), and Urbach et al. } \\
\text { (2010) }\end{array}$ \\
\hline Compliance & $\begin{array}{l}\text { Content deletion, local content } \\
\text { storage, change traceability, content } \\
\text { protection, history recording }\end{array}$ & $\begin{array}{l}\text { New items derived from Chiu and Hung (2005), } \\
\text { Munkvold et al. (2006), Nordheim and Päivärinta } \\
\text { (2006), and Vom Brocke et al. (2011c) }\end{array}$ \\
\hline
\end{tabular}

\subsection{Data Collection}

We compiled an online survey in English, German, and French, ensuring consistency among the three language versions by translating the questions back and forth among the languages. For the data collection, we contacted several companies and public administrations, providing them a description of the study and offering them to conduct this study in their companies to evaluate their ECMS. Four companies/institutions agreed to participate:

\begin{tabular}{|lccc|}
\hline \multicolumn{3}{c|}{ Table 4. Participating Companies } \\
\hline No & Branch & Employees (approx.) & Turnover in Euro (approx.) \\
\hline 1 & Ceramics & 8000 & 750 million \\
2 & Dental & 3200 & 700 million \\
3 & Enterprise & 74000 & 17 billion \\
4 & Education & 1600 & - \\
\hline
\end{tabular}

Each of the organizations invited between thirty and one thousand users to participate in the survey. The survey was designed for both users and nonusers of the company's ECMS. Users had to fill in the entire 
survey, and nonusers were directed to a short version of the survey that explored the reasons for not using the system. Because both users and nonusers were invited to participate in the survey and because we used only the users' responses for our data analysis, we cannot derive an exact response rate for the four cases. Still, we tried to avoid non-response bias as much as possible by following the recommendations of Rogelberg and Stanton (2007) concerning for example layout, informing participants etc.

We also checked the responses to the organizational studies for non-response bias by applying the MannWhitney U test (Mann and Whitney, 1947) to test for differences in the groups of early (first half of the survey period) and late (second half) respondents. The results did not indicate any differences, so nonresponse bias is not likely to be an issue in our study. The four organizational studies resulted in 225 valid data sets after data cleaning, which is an acceptable number for our study (Chin, 1998).

We also tested the data for common method bias (CMB), which occurs when variance is attributable to the method of measurement rather than to the constructs the measures represent (Podsakoff et al., 2003). We tested the data for CMB by applying Harman's single-factor test (Podsakoff et al., 2003, Malhotra et al., 2006), which is built on an exploratory factor analysis to investigate the unrotated factor solution. The solution resulted in ten factors with an Eigenvalue greater than 1.0 that explained 65.6 percent of the total variance. The first factor explained 32.1 percent of the variance, which is less than a third of the variance explained. Because the solution did not provide only a single factor and because the first factor of the EFA solution did not explain the majority of the variance (Malhotra et al., 2006), we concluded that CMB is not an issue in our study.

\section{Analysis and Results}

The model we derived is a relatively complex model that incorporates many constructs with interrelationships and involves latent variables. Therefore, we empirically evaluated our model using the SEM technique, specifically the PLS algorithm. PLS is particularly suitable for this data analysis because of its ability to work with reflective and formative constructs (Chin, 1998), because it requires no data distribution form (Fornell and Bookstein, 1982), and because it makes lower demands on the required sample size then covariance-based SEM (Urbach and Ahlemann, 2010). This section describes the model validation of both measurement models and the structural model. We used the software packages SmartPLS 2.0.M3 (Ringle et al., 2005) and IBM SPSS Statistics 21 (Ibm Corp., Released 2012) for the statistical analyses and calculations.

\subsection{Assessment of Measurement Models}

Our ECMS success model consists primarily of reflective constructs; only use was operationalized formatively. We followed the recommendations of Straub et al. (2004), Lewis et al. (2005), and Urbach and Ahlemann (2010) to validate the measurement models by testing the reflective measurement model for unidimensionality, internal consistency reliability, indicator reliability, convergent validity, and 
discriminant validity and the formative measurement model for indicator and construct validity.

We tested for unidimensionality by performing an exploratory factor analysis (EFA) that shows whether an item loads high on only one factor and whether all items load highest on the one factor they are supposed to measure. In conducting the EFA, we used principal axis factoring as the extraction method and applied a promax rotation with Kaiser normalization. The results of the factor analysis (Appendix C) showed one item that did not load on its intended factor, so we eliminated the item from the set of variables and repeated the EFA. The final results demonstrate an appropriate level of unidimensionality, as all items load high on only one factor. Except for six loadings, all loadings have a value above .600, which is considered high. Only one factor has a loading below .400 and five item loads between .400 and .600. However, because these items still load highest on their corresponding factors, we kept them for further analysis.

We also tested the data for internal consistency reliability. This can be assessed by two measures: Cronbach's alpha (CA) and composite reliability (CR). CA measures the degree to which a set of items measures a single latent construct (Henson, 2001). CR, the other measure for internal consistency reliability has been suggested as the preferred measure of internal consistency reliability because it overcomes some of the deficiencies of CA (Chin, 1998). All of the construct's CA and CR values meet the recommended threshold of .700 (Nunnally and Bernstein, 1994). Four of the constructs show values above .950 , which might suggest the presence of a CMB (Straub et al., 2004), but our tests for CMB showed that this was unlikely.

Next, we tested the items for indicator reliability, by drawing on the item loadings by means of confirmatory factor analysis, as provided by SmartPLS. The recommended threshold for reliable items is .700, which was met by all items except one, which we excluded it from further analysis. To test for significance of the indicator loadings, we used bootstrapping with the minimum sample size of 5,000, as recommended by Hair et al. (2011). The results indicate that all loadings are above 3.29 and as such are significant at the .001 level (Appendix D).

\begin{tabular}{|lccc|}
\hline \multicolumn{4}{c}{ Table 5. Internal consistency and convergent validity } \\
\hline & Cronbach's alpha & Composite reliability & Average variance extracted \\
\hline Collaboration & .876 & .915 & .730 \\
Compliance & .870 & .906 & .658 \\
Efficiency & .894 & .927 & .761 \\
Individual impact & .971 & .977 & .896 \\
Information quality & .879 & .912 & .675 \\
Process quality & .938 & .953 & .802 \\
Service quality & .934 & .950 & .793 \\
System quality & .929 & .947 & .781 \\
User satisfaction & .958 & .967 & .856 \\
\hline
\end{tabular}

Further we assessed convergent reliability through the average variance extracted (AVE) criterion as proposed by Fornell and Larcker (1981). The results in Table 5 show that all our constructs met the 
recommended threshold above .500 , suggesting that all constructs have a reasonable level of validity.

The finale criterion for measuring the reflective constructs is discriminant validity. We used two criteria to measure discriminant validity: the cross loadings of the items and the Fornell-Larcker criterion. The crossloadings indicate that the loading of each indicator is the highest on its designated construct and that each construct loads highest on its associated items (Appendix E). To determine whether all measures differ from each other, we assessed the Fornell-Larcker criterion. Table 6 shows that all squared roots of the AVE meet this criterion, suggesting that the constructs significantly differ from each other.

\begin{tabular}{|c|c|c|c|c|c|c|c|c|c|}
\hline & $\mathrm{CL}$ & $\mathrm{CP}$ & $\mathrm{EF}$ & II & IQ & PQ & SE & SQ & US \\
\hline CL: Collaboration & .854 & & & & & & & & \\
\hline CP: Compliance & .475 & .811 & & & & & & & \\
\hline EF: Efficiency & .753 & .586 & .872 & & & & & & \\
\hline Individual impact & .692 & .410 & .710 & .947 & & & & & \\
\hline IQ: Information quality & .403 & .246 & .439 & .450 & .822 & & & & \\
\hline PQ: Process quality & .651 & .462 & .658 & .674 & .425 & .895 & & & \\
\hline SE: Service quality & .443 & .241 & .404 & .304 & .353 & .484 & .890 & & \\
\hline SQ: System quality & .562 & .376 & .645 & .646 & .498 & .590 & .375 & .884 & \\
\hline US: User satisfaction & .713 & .432 & .737 & .780 & .429 & .664 & .439 & .760 & .925 \\
\hline
\end{tabular}

Next, we assessed the formative measurement model. Our model contains only one formative construct, use. As recommended by Henseler et al. (2009), we examined the indicator validity and the construct validity to assess the formative construct. To assess the indicator validity, we examined the weights of the items and the variance inflation factor (VIF). Of the six use items, the weights of two items do not meet the recommended threshold of .100 and four of the items do not meet a minimum significance level of .010. (Hair et al., 2011) (Appendix F). However, we decided to keep the items although the threshold was not met because eliminating items from a formative construct would exclude a unique descriptive part of the construct and as such altering its meaning (Jarvis et al., 2003). We also tested the use items for multicollinearity, through the VIF, which measures to what degree the variance is inflated. To exclude multicollinearity, the items must meet the commonly accepted VIF threshold of less than 10 (Diamantopoulos and Winklhofer, 2001), which all of the use items met. Therefore, multicollinearity is not likely to be an issue in this construct.

Finally, we tested the formative constructs for construct validity by testing for discriminant validity. We used the correlations between the formative construct use and all the other constructs and found reasonable discriminant validity because all correlations between the use construct and the other constructs are less than .700 (Appendix G).

\subsection{Assessing the Structural Model}

Having validated our measurement model, we assessed the appropriateness of our structural model and tested our hypothesis. Because PLS cannot test mutual relationships simultaneously, such as that between use and user satisfaction in our model, we had to test two models: Model A, which hypothesizes that use 
influences user satisfaction (H9), and model B, which hypothesizes that user satisfaction influences use (H10). The results of our analysis of both models are shown in Figure 2. We used bootstrapping with 5,000 samples, as suggested by Hair et al. (2011), to test the significance of the resulting path coefficients.

We followed the recommendations of Urbach and Ahlemann (2010) in using the coefficient of determination $\left(\mathrm{R}^{2}\right)$, path coefficients $(\beta)$ and effect size $\left(f^{2}\right)$ to assess the structural model. Both models explain a great portion of the variance of the latent constructs. User satisfaction $\left(\mathrm{R}^{2}{ }_{\mathrm{A}}=.671, \mathrm{R}^{2}{ }_{\mathrm{B}}=.655\right)$ and individual impact $\left(\mathrm{R}_{\mathrm{A}}^{2}=.662, \mathrm{R}^{2}{ }_{\mathrm{B}}=.664\right)$ explain more than half of the variance. This applies also for efficiency $\left(\mathrm{R}_{\mathrm{A}}^{2}=.596, \mathrm{R}_{\mathrm{B}}^{2}=.597\right)$ as well as collaboration $\left(\mathrm{R}_{\mathrm{A} / \mathrm{B}}^{2}=.562\right)$ of the three organizational impact dimensions. Of the three organizational-impact constructs, compliance has the lowest level of variance explained, with a rather weak level of $\mathrm{R}^{2}\left(\mathrm{R}_{\mathrm{A} / \mathrm{B}}^{2}=.203\right.$. Of the constructs originating of the D\&M IS success model, has use the lowest $\mathrm{R}^{2}\left(\mathrm{R}^{2}{ }_{\mathrm{A}}=.215, \mathrm{R}^{2}{ }_{\mathrm{B}}=.249\right)$ in both models.

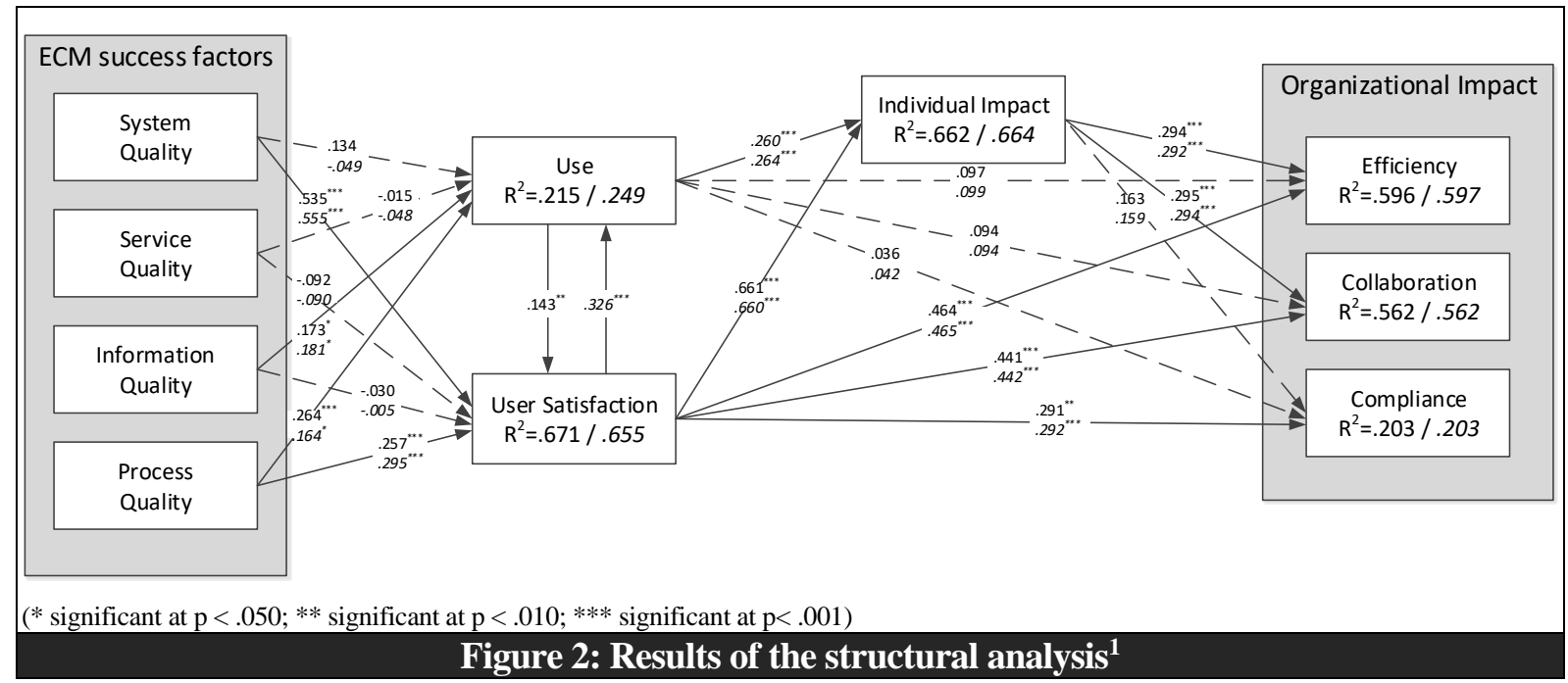

In the next step, we assessed the path coefficients between the model's latent variables. In particular, we checked the path coefficients for their signs, as well as their magnitude. We applied the threshold of .100, which assumes a substantial impact in the model (Urbach and Ahlemann, 2010), and also determined that the path coefficient should be significant at least at the .050 level. To assess the significance of the path coefficients, we applied the bootstrapping technique with 5.000 samples (Hair et al., 2011). Of the paths between use and the quality constructs, only two paths information quality $\rightarrow$ use $\left(\beta_{\mathrm{A}}=.173, \beta_{\mathrm{B}}=.181\right)$ and process quality $\rightarrow$ use $\left(\beta_{\mathrm{A}}=.264, \beta_{\mathrm{B}}=.165\right)$ reach the threshold of .100 and are significant at a minimum of .050 level. That applies to the paths between the quality constructs and the user satisfaction construct too, only two paths - system quality $\rightarrow$ user satisfaction $\left(\beta_{\mathrm{A}}=.535\right.$,

\footnotetext{
${ }^{1}$ Upper path coefficient represents model A and the italic lower ones represent model B.
} 
$\left.\beta_{\mathrm{B}}=.555\right)$ and process quality $\rightarrow$ user satisfaction $\left(\beta_{\mathrm{A}}=.257, \beta_{\mathrm{B}}=.295\right)$-, show a value above .100 at a significance level of at least .050. None of the paths between use and the three organizational impact constructs reach the threshold of .100 and as such cannot be supported, while all paths between user satisfaction and the organizational impact constructs efficiency $\left(\beta_{\mathrm{A}}=.464, \beta_{\mathrm{B}}=.465\right)$, collaboration $\left(\beta_{\mathrm{A}}\right.$ $\left.=.441, \beta_{\mathrm{B}}=.442\right)$, and compliance $\left(\beta_{\mathrm{A}}=.291, \beta_{\mathrm{B}}=.292\right)$ are above the threshold and significant at at least .050 and thus are supported by the data. Except the path between individual impact and compliance $\left(\beta_{\mathrm{A}}=.163, \beta_{\mathrm{B}}=.159\right)$ which is not significant, show all other path coefficients in our model values above .100 - most are above .200 - with user satisfaction $\rightarrow$ individual impact having the highest value $\left(\beta_{\mathrm{A}}\right.$ $\left.=.661, \beta_{\mathrm{B}}=.660\right)$, system quality $\rightarrow$ user satisfaction the second highest value $\left(\beta_{\mathrm{A}}=.535, \beta_{\mathrm{B}}=.555\right)$, and user satisfaction $\rightarrow$ efficiency the third highest value $\left(\beta_{\mathrm{A}}=.464, \beta_{\mathrm{B}}=.465\right)$.

\begin{tabular}{|llllll|}
\multicolumn{7}{r}{ Table 7: Results of hypotheses testing } & & \\
\hline Hypothesis & $\beta$ & $f^{2}$ & Support & Effect size \\
\hline H1 & System quality $\rightarrow$ use & $.134 /-.059$ & $.013 / .001$ & No & - \\
H2 & System quality $\rightarrow$ user satisfaction & $.535^{* * *} / .555^{* * *}$ & $.495 / .512$ & Yes & Large \\
H3 & Service quality $\rightarrow$ use & $-.015 /-.048$ & $.000 / .002$ & No & - \\
H4 & Service quality $\rightarrow$ user satisfaction & $.092 / .090$ & $.018 / .017$ & No & - \\
H5 & Information quality $\rightarrow$ use & $.173^{*} / .181^{*}$ & $.029 / .026$ & Yes & Small \\
H6 & Information quality $\rightarrow$ user satisfaction & $-.030 /-.005$ & $.002 /-.001$ & No & - \\
H7 & Process quality $\rightarrow$ use & $.264^{* * *} / .165^{*}$ & $.050 / .018$ & Yes & Small \\
H8 & Process quality $\rightarrow$ user satisfaction & $.257^{* * *} / .295^{* * *}$ & $.109 / .141$ & Yes & Small \\
H9 & Use $\rightarrow$ user satisfaction & $.143^{* * *} /-$ & $.048 /-$ & Yes & Small \\
H10 & User satisfaction $\rightarrow$ use & $-/ .326^{* * *}$ & $-/ .046$ & Yes & Small \\
H11 & Use $\rightarrow$ individual impact & $.260^{* * *} / .264^{* * *}$ & $.157 / .164$ & Yes & Medium \\
H12 & User satisfaction $\rightarrow$ individual impact & $.661^{* * *} / .660^{* * *}$ & $1.018 / 1.031$ & Yes & Large \\
H13 & Individual impact $\rightarrow$ efficiency & $.294^{* * *} / .292^{* * *}$ & $.073 / .071$ & Yes & Small \\
H14 & Individual impact $\rightarrow$ collaboration & $.295^{* * *} / .294^{* * *}$ & $.066 / 067$ & Yes & Small \\
H15 & Individual impact $\rightarrow$ compliance & $.159 / .163$ & $.009 / .008$ & No & - \\
H16 & Use $\rightarrow$ efficiency & $.097 / .099$ & $.016 / .016$ & No & - \\
H17 & Use $\rightarrow$ collaboration & $.094 / .094$ & $.014 / .014$ & No & - \\
H18 & Use $\rightarrow$ compliance & $.036 / .042$ & $.001 / 001$ & No & - \\
H19 & User satisfaction $\rightarrow$ efficiency & $.464 / .465$ & $.209 / .210$ & Yes & Medium \\
H20 & User satisfaction $\rightarrow$ collaboration & $.441 / .442$ & $.176 / .176$ & Yes & Medium \\
H21 & User satisfaction $\rightarrow$ compliance & $.291 / .292$ & $.042 / .043$ & Yes & Small \\
\hline
\end{tabular}

Finally, we calculated the effect size of one variable to another by calculating the Cohen's effect size $f^{2}$ (Cohen, 1988). The effect size is calculated by assessing the increase in $\mathrm{R}^{2}$ of the variable connected relative to the variable's unexplained variance (Chin, 1998). Effect sizes $f^{2}$ of $.020, .150$, and .350 determine whether the effect on the endogenous variable is small, medium, or large, respectively (Chin, 1998, Wong, 2013). All paths that are significant in our model show at least a small effect size. The results of the assessment of the hypotheses are summarized in Table 7.

\section{Discussion}

Most our hypotheses are supported by the results of our study. However, only half of the paths between use and the quality dimensions and between user satisfaction and the quality dimensions are supported; the supported paths are system quality $\rightarrow$ user satisfaction, process quality $\rightarrow$ user satisfaction, information 
quality $\rightarrow$ use, and process quality $\rightarrow$ use. No paths between service quality, use, and user satisfaction could be confirmed. These results suggest that the quality dimensions in general play a minor role on the success of ECMS. Only four of the eight paths could be confirmed by the data. Use is influenced only by information quality, process quality and user satisfaction. The relationship between information quality and use seems logical: many organizations have issues with the quality of their information and often organizations hope to improve their information quality through ECM (e.g., Vom Brocke et al., 2011a, Munkvold et al., 2006). If an ECMS holds high quality information, users are more likely to use the ECMS to retrieve this information. This might be similar with the relationship between process quality and use. Next to information quality, organizations often implement ECMS to simplify and improve their processes (e.g., Smith and Mckeen, 2003, Päivärinta and Munkvold, 2005, O'callaghan and Smits, 2005). If an ECMS is part of a user's processes, it is more likely that he or she uses or must use the ECMS to execute the process successfully. This might also explain the non-significant impact of system quality on use: if an ECMS is part of a user's processes or if an ECMS is the only source for certain kind of information in an organization a user might just not have the option to avoid the use of an ECMS. Other ECM-related success studies show similar findings. Urbach et al. (2010), for example, could not find support for the relationships between use and the quality dimensions of system, service, information as well as process quality.

The analysis of our model shows that only two quality constructs, system quality and process quality, have a significant impact on the user satisfaction construct. A meta-study of IS success articles confirmed that there is a strong support between system quality and user satisfaction, and ECM-related success studies have also confirmed this finding (e.g., Kulkarni et al., 2007, Urbach et al., 2010). The additional quality construct process quality was suggested by Urbach et al. (2010), whose study supported the relationship between process quality and user satisfaction, although their effect size on the path was lower than the results in our study. Therefore, support of an employee's work processes appears to influence his or her satisfaction with the ECMS. Interestingly, process quality is the only independent variable which influences both use and user satisfaction and as such seem to play an important role for ECMS success.

The constructs information quality and service quality have no influence on user satisfaction. The missing support between service quality and user satisfaction is not surprising, given that a meta-analysis among IS success studies shows only mixed results for this relationship (Petter et al., 2008) and that ECM-related studies (e.g., Urbach et al., 2010, Paré et al., 2005) could not confirm a relationship. Perhaps the missing support for this relationship is because service requests usually appear after a system is newly implemented or after a user has just received access to the system, after which service requests continuously decrease. We determined that most our respondents had at least one year of experience with the ECMS, so they probably don't need service support often anymore. In contrast to the majority of IS success studies (Petter et al., 2008), our study did not confirm the relationship between information quality and user satisfaction. This is not surprising as the goal of ECMS is usually to deliver high-quality information. Therefore, it can 
be assumed that the information quality is already high. (This supposition is also indicated by a high index value of 5.29 on a seven-point Likert scale and a STD of 1.108. see Appendix I).

Use and user satisfaction both have a considerable effect on individual impact, the impact of the ECMS on the individual user. While use has only a medium effect on individual impact, the effect of user satisfaction on individual impact is large. This result is in line with the original model suggested by DeLone and McLean $(2003,1992)$ and a meta-analysis of previous success studies (Petter et al., 2008). The results also show that use has no direct influence on the three organizational impact dimensions efficiency, collaboration and compliance. However, the data further suggests that efficiency and collaboration are influenced only by the individual impact which results from ECMS use. To test this assumption, we conducted a mediation analysis with structural equation modeling (Gunzler et al., 2013) and the results confirm a complete mediation between use and efficiency as well as use and collaboration through individual impact. An explanation for the missing impact of use on the organizational impact constructs could be of how ECMS use was assessed. In this study, we assessed use through the extent users are using different functionalities of the ECMS as well as the frequency of use. However, neither use of functionalities nor the frequency of use give any evidence about the quality of ECMS use. An ECMS can be used on a very basic level, for example, a user might upload a certain document to the system, maybe because he has to do so, but he might not add any meta data to the document which would make the document easier to find and assign it to specific people or cases. In this case the ECMS use quality would be rather low and as such probably has no impact on the organization. This is also in line with the fact that all paths between user satisfaction and the three organizational impact dimensions efficiency, collaboration and compliance are supported by our data. So, the impact of the ECMS on the organization is not just influenced by the ECMS' impact on the individual but also on the users' satisfaction with the ECMS. This means a high satisfaction of the user with the ECMS not just influences the performance of the individual itself, but at the same time it leads to a higher organizational efficiency, collaboration and increased level of compliance. Therefore, to realize the three ECM objects efficiency, collaboration, and compliance, organizations should put attention to the users' satisfaction with the ECMS and in particular check for system's and process quality as these factors influence users' satisfaction.

The results of the data show a strong $\mathrm{R}^{2}$ value for two of the three impact constructs, efficiency, and collaboration, and a rather weak $\mathrm{R}^{2}$ of compliance, yet suggesting that all three constructs are valid factors for explaining ECMS success. Furthermore, it is likely that ECMS can help organizations to increase the efficiency of their content management, to raise their collaboration capabilities in terms of content management, and to improve their compliance concerning content handling. The majority of ECM-related success studies haven't assessed the organizational impact at all (e.g., Paré et al., 2005, Adeyinka and Mutula, 2010, Kulkarni et al., 2007) or have done so only by a single construct (e.g., Urbach et al., 2010). However, using only a single construct for this purpose does not allow the researcher to draw conclusions concerning whether the IS can help to achieve the goals an organization was pursuing by implementing 
ECMS or not. Therefore, organizational impact should be assessed in terms of the organization's specific goals, which is in line with the finding of Delone and Mclean (2003) in their e-commerce example, where they stated that "net benefits measures must be determined by context and objectives" (p. 25).

In summary, information quality, system quality, process quality, use, user satisfaction, individual impact, collaboration, efficiency, and compliance are important factors in evaluating the success of ECMS, while service quality is less important, if it has an effect at all. The results also suggest that the D\&M IS success model (Delone and Mclean, 2003, Delone and Mclean, 1992) is a suitable lens through which to study ECMS success if the model is respecified in terms of the quality dimensions and the dimensions of the organizational impact.

\section{Conclusion}

This article proposes a respecified ECMS success model that is grounded in the D\&M IS success model (Delone and Mclean, 2003, Delone and Mclean, 1992). We extended the D\&M IS success model by one quality dimension, process quality, as suggested by Urbach et al. (2010) and refined the organizational impact construct by adding three sub-constructs that reflect specific organizational ECM objectives reported in the literature: efficiency, collaboration, and compliance. Our results indicate that only three antecedent factors are important to ECMS success: information quality, system quality, and process quality, while process quality is the only factor that influences both, ECMS usage and users' satisfaction with the ECMS. Concerning the three organizational-impact dimensions, our results suggest that assessing ECMS success based on specific ECM objectives is beneficial, as doing so would reveal more detail about the impact of ECMS on organizations. The results also show that the organizational impact in terms of efficiency, collaboration and compliance is not directly influenced by ECMS use but mediated through individual impact. However, the three impact dimensions are influenced by the users' satisfaction with the ECMS.

Our research has some limitations, one of which concerns our explanation for our unconfirmed hypotheses. Although we provided some explanations for these missing links, our data did not allow us to test our explanations. Future research should investigate the reasons for the missing relationship between the constructs by means of exploratory research.

The data collection process also led to some limitations. The study builds on convenience sampling of organizations. Data collection through random sampling would have allowed for a higher degree of generalizability. Another limitation lies in the selection of the participants. The organizations selected their participants directly and the researchers had no control over this step.

The results of our research show that only three of the independent variables, information quality, system quality, and process quality, influence the success of ECMS. This suggests that further research is needed to assess the factors that determine ECMS success in more detail, for example, by investigating the critical 
success factors for ECM that have been presented in the literature (e.g., Wiltzius et al., 2011). The research also shows that ECM positively affects the content management in terms of efficiency, collaboration, and compliance.

Developing an ECMS success model contributes to academia and practice in several ways. For practitioners, the model provides three antecedent factors that influence the success of ECMS. Practitioners can monitor these factors as performance indicators to improve users' satisfaction with the ECMS and, thus, the success of their ECMS, possibly using the survey instrument to assess these factors. Furthermore, the dimensions proposed in our model as well as the relationships between the success dimensions can support practitioners in understanding the multiple facets of ECMS success to improve how they plan and prepare for ECM investments. In addition, the three dimensions of the organizational impact - efficiency, collaboration, and compliance-allow organizations to justify their ECM investments and to better monitor the effect of the ECMS on the organization.

Our research also contributes to theory by extending and empirically testing the D\&M IS success model in a new domain and system context. Our research is the first to test empirically and validate a comprehensive ECMS success model that extends knowledge related to ECM by examining the relationship between the quality dimensions and the success measures. Our research shows that only three quality dimensions - information quality, system quality and process quality - affect the success of ECMS, suggesting that additional influencing dimensions should be investigated. We also shed some light on the organizational perspective by adding specific ECM objectives to the model. Most IS success studies have been conducted on the individual level, neglecting the organizational perspective. We evaluate the organizational impact of ECMSs, adding more specific organizational-impact constructs to the model that represent certain organizational ECM goals because having only one organizationalimpact construct is not sufficient to theorize on the effect of an ECMS. As a result, our model contributes to clarifying what organizations can gain by implementing ECM. 


\section{References}

Adeyinka, T. and Mutula, S. (2010), "A proposed model for evaluating the success of WebCT course content management system", Computers in Human Behavior, 26, pp. 1795-1805.

AIIM (n.d.), "What is Enterprise Content Management (ECM)?", available at: http://www.aiim.org/Whatis-ECM-Enterprise-Content-Management (accessed March 29, 2013).

Alalwan, J. A. and Weistroffer, H. R. (2012), "Enterprise content management research: A comprehensive review", Journal of Enterprise Information Management, 25, pp. 441-461.

Allen, D. (2007), "Cost/Benefit Analysis for Implementing ECM, BPM Systems", The Information Management Journal, 41, pp. 34-41.

Andersen, R. (2007), "The rhetoric of enterprise content management (ECM): Confronting the assumptions driving ECM adoption and transforming technical communication", Technical Communication Quarterly, 17, pp. 61-87.

ARMA International (2013), "Compliance/Risk Management", available at: http://www.arma.org/compliance/ (accessed 10 April 2013).

Bailey, J. E. and Pearson, S. W. (1983), "Development of a Tool for Measuring and Analyzing Computer User Satisfaction", Management Science, 29, pp. 530-545.

Chambers, B. (2007), "BPM: how does it fit into an ECM strategy", AIIM e-doc magazine, 21, pp. 36-9.

Chin, W. W. (1998). "The Partial Least Squares Approach to Structural Equation Modeling". Marcoulides, G. A. (ed.) Modern Methods for Business Research. Lawrence Erlbaum, Mahwah, NJ, pp. 295-336.

Chiu, D. K. W. and Hung, P. C. K. "Privacy and Access Control Issues in Financial Enterprise Content Management". 38th Hawaii International Conference on System Sciences (HICCS '05), 20052005 Big Island, USA. Index 12.

Cohen, J. (1988), Statistical power analysis for the behavioral sciences (2nd Ed.), Lawrence Erlbaum Associates, Inc., Hillsday, NJ, USA.

Davis, F. D. (1989), "Perceived usefulness, perceived ease of use, and user acceptance of information technology", Management Information Systems Quarterly, 13, pp. 319-340.

DeLone, W. H. and McLean, E. R. (1992), "Information Systems Success: The Quest for the Dependent Variable", Information Systems Research, 3, pp. 60-95.

DeLone, W. H. and McLean, E. R. (2003), "The DeLone and McLean Model of Information Systems Success: A Ten-Year Update", Journal of Management Information Systems, 19, pp. 9-30.

Diamantopoulos, A. and Winklhofer, H. M. (2001), "Index construction with formative indicators: an alternative to scale development", Journal of Marketing research, 38, pp. 269-277.

Dilnutt, R. (2006), "Surviving the Information Explosion", Engineering Management, 16, pp. 39-41.

Fornell, C. and Bookstein, F. L. (1982), "Two Structural Equation Models: LISREL and PLS Applied to Consumer Exit-Voice Theory", Journal of Marketing Research, 19, pp. 440-452.

Fornell, C. and Larcker, D. F. (1981), "Evaluating Structural Equation Models with Unobservable Variables and Measurement Error", Journal of Marketing Research, 18, pp. 39-50.

Frappaolo, C. (2008), "BPM \& ECM - Don't Do One Without the Other", available at: http://www.takingaiim.com/2008/09/the-slide-prese.html (accessed 20. May 2011).

Gable, G. and Rai, A. "Reconceptualising the information system as a service". 17th European Conference on Information Systems (ECIS '09), June 8-10, 20092009 Verona, Italy.

Gable, G., Sedera, D. and Chan, T. "Enterprise Systems Success: A Measurement Model". 24th International Conference on Information Systems (ICIS '03), December 14-17, 20032003 Seattle, USA. pp. 576-591.

Gartner (2014), "Magic Quadrant for Enterprise Content Management", available at: http://www.projectconsult.de/files/Gartner_ECM_MQ_2014.pdf (accessed 25. August 2015).

Gilchrist, A. (2001), "Corporate Taxonomies: Report on a Survey of Current Practice", Online Information Review, 25, pp. 94-103.

Grahlmann, K. R., Helms, R. W., Hilhorst, C., Brinkkemper, S. and van Amerongen, S. (2012), "Reviewing enterprise content management: A functional framework", European Journal of Information Systems, 21, pp. 268-286.

Gunasekaran, A., Marri, H., McGaughey, R. and Nebhwani, M. (2002), "E-Commerce and Its Impact on Operations Management", International Journal of Production Economics, 75, pp. 185-197. 
Gunzler, D., Chen, T., Wu, P. and Zhang, H. (2013), "Introduction to mediation analysis with structural equation modeling", Shanghai Archives of Psychiatry, 25, pp. 390-394.

Hair, J. F., Ringle, C. M. and Sarstedt, M. (2011), "PLS-SEM: Indeed a silver bullet", The Journal of Marketing Theory and Practice, 19, pp. 139-152.

Halawi, L., McCarthy, R. V. and Aronson, J. E. (2008), "An emprirical investigation of Knowledge Management Systems' Success", Journal of Computer Information Systems, 48, pp. 121-137.

Henseler, J., Ringle, C. M. and Sinkovics, R. R. (2009). "The use of partial least squares path modeling in international marketing". Sinkovics, R. R. and Ghauri, P. N. (eds.) Advances in international marketing. Emerald Group Publishing Limited, pp. 277-319.

Henson, R. K. (2001), "Understanding internal consistency reliability estimates: A conceptual primer on coefficient alpha", Measurement and evaluation in counseling and development, 34, pp. 177-189.

Herbst, A., Simons, A., vom Brocke, J. and Derungs, R. (2014a). "Critical Success Factors in Enterprise Content Management: Toward a Framework for Readiness Assessment". Vom Brocke, J. and Simons, A. (eds.) Enterprise Content Management in Information Systems Research: Foundations and Cases. Springer, Berlin, pp. 109-124.

Herbst, A., Urbach, N. and Brocke, J. v. "Shedding Light on the Impact Dimension of Information Systems Success: A Synthesis of the Literature". 47th Annual Hawaii International Conference on System Sciences (HICSS '14), 2014b Big Island, HI.

IBM Corp. (Released 2012), IBM SPSS Statistics for Windows, Version 21.0, IBM Corp, Armonk, NY.

Iivari, J. (2005), "An empirical test of the DeLone-McLean model of information system success", ACM SIGMIS Database, 36, pp. 8-27.

Iverson, J. and Burkart, P. (2007), "Managing Electronic Documents and Work Flows: Enterprise Content Management at Work in Nonprofit Organizations", Nonprofit Management and Leadership, 17, pp. 403-419.

Jarvis, C. B., MacKenzie, S. B. and Podsakoff, P. M. (2003), "A critical review of construct indicators and measurement model misspecification in marketing and consumer research", Journal of consumer research, 30, pp. 199-218.

Kampffmeyer, U. (2006), "ECM - Enterprise Content Management", available at: http://projectconsult.net/Files/ECM_White\%20Paper_kff_2006.pdf (accessed August 14, 2013).

Kulkarni, U. R., Ravindran, S. and Freeze, R. (2007), "A Knowledge Management Success Model: Theoretical Development and Empirical Validation", Journal of Management Information Systems, 23, pp. 309-347.

Kwok, K. H. S. and Chiu, D. K. W. "A Web Services Implementation Framework for Financial Enterprise Content Management". 37th Hawaii International Conference on System Sciences (HICSS '04), January 5-8, 20042004 Big Island, Hawaii, USA. Index 11.

Lewis, B. R., Templeton, G. F. and Byrd, T. A. (2005), "A methodology for construct development in MIS research", European Journal of Information Systems, 14, pp. 388-400.

Lin, H.-F. (2007), "Measuring Online Learning Systems Success: Applying the Updated DeLone and McLean Model", CyberPsychology \& Behavior, 10, pp. 817-820.

Malhotra, N. K., Kim, S. S. and Patil, A. (2006), "Common Method Variance in IS Research: A Comparison of Alternative Approaches and a Reanalysis of Past Research", Management Science, 52, pp. 1865-1883.

Maltz, A. C., Shenhar, A. J. and Reilly, R. R. (2003), "Beyond the Balanced Scorecard: Refining the Search for Organizational Success Measures", Long Range Planning, 36, pp. 187-204.

Mann, H. B. and Whitney, D. R. (1947), "On a test of whether one of two random variables is stochastically larger than the other", The annals of mathematical statistics, pp. 50-60.

Moore, G. C. and Benbasat, I. (1991), "Development of an Instrument to Measure the Perceptions of Adopting an Information Technology Innovation", Information Systems Research, 2, pp. 192-222.

Munkvold, B. E., Päivärinta, T., Hodne, A. K. and Stangeland, E. (2006), "Contemporary issues of enterprise content management: The case of Statoil", Scandinavian Journal of Information Systems, 18, pp. 69-100.

Nordheim, S. and Päivärinta, T. (2006), "Implementing enterprise content management: From evolution through strategy to contradictions out-of-the-box", European Journal of Information Systems, 15, pp. 648-662.

Nunnally, J. C. and Bernstein, I. H. (1994), Psychometric Theory, MdGraw-Hill, New York, NY. 
O'Callaghan, R. and Smits, M. 2005. A strategy development process for enterprise content management. 13th European Conference on Information Systems (ECIS 2005). Regensburg, Germany.

Päivärinta, T. and Munkvold, B. E. "Enterprise content management: An integrated perspective on information management". 38th Annual Hawaii International Conference on System Sciences (HICSS '05), January 3-6, 20052005 Big Island, HI, USA.

Paré, G., Lepanto, L., Aubry, D. and Sicotte, C. (2005), "Toward a multidimensional assessment of picture archiving and communication system success", International Journal of Technology assessment in Health Care, 21, pp. 471-479.

Petter, S., DeLone, W. and McLean, E. R. (2008), "Measuring Information Systems Success: Models, Dimensions, Measures, and Interrelationships", European Journal of Information Systems, 17, pp. 236-263.

Petter, S., DeLone, W. and McLean, E. R. (2012), "The Past, Present, and Future of "IS Success"', Journal of the Association for Information Systems, 13, pp. 341-362.

Pitt, L. F., Watson, R. T. and Kavan, C. B. (1995), "Service Quality: A Measure of Information Systems Effectiveness", Management Information Systems Quarterly, 19, pp. 173-187.

Podean, M. I., Benta, D. and Costin, R. A. "On Supporting Creative Interaction in Collaborative Systems: A Content Oriented Approach". 13th Conference on Commerce and Enterprise Computing (CEC '11) September 5-7, 20112011 Luxembourg, Luxembourg. pp. 400-406.

Podsakoff, P. M., MacKenzie, S. B., Lee, J.-Y. and Podsakoff, N. P. (2003), "Common method biases in behavioral research: a critical review of the literature and recommended remedies", Journal of applied psychology, 88, pp. 879-903.

Pullman, G. and Gu, B. (2008), "Guest editors' introduction: Rationalizing and rhetoricizing content management", Technical Communication Quarterly, 17, pp. 1-9.

Radicati Group (2013), "Enterprise content management market, 2013-2017", available at: http://www.radicati.com/wp/wp-content/uploads/2013/05/Enterprise-Content-Management-Market2013-2017-Executive-Summary.pdf (accessed August. 21 2013).

Recker, J. C. and Rosemann, M. (2010), "A Measurement Instrument for Process Modeling research: Development, Test and Procedural Model", Scandinavian Journal of Information Systems, 22, pp. 330.

Rickenberg, T., Neumann, M., Hohler, B. and Breitner, M. "Enterprise content management - A literature review". 18th Americas Conference on Information Systems (AMCIS '12), August 9-11, 20122012 Seattle, WA, USA.

Ringle, C., Wende, S. and Will, A. (2005), "SmartPLS", available at: http://www.smartpls.de (accessed 05 April 2013).

Rockley, A., Kostur, P. and Manning, S. (2003), Managing Enterprise Content: A Unified Content Strategy, New Riders, Berkley, CA.

Rogelberg, S. G. and Stanton, J. M. (2007), "Introduction understanding and dealing with organizational survey nonresponse", Organizational Research Methods, 10, pp. 195-209.

Scott, J., Globe, A. and Schiffner, K. (2004), "Jungles and Gardens: The Evolution of Knowledge Management at JD Edwards", MIS Quarterly Executive, 3, pp. 37-52.

Seddon, P. B. (1997), "A respecification and extension of the DeLone and McLean model of IS success", Information Systems Research, 8, pp. 240-253.

Seddon, P. B., Staples, S., Patnayakuni, R. and Bowtell, M. (1999), "Dimensions of information systems success", Communications of the Association for Information Systems, Vol. 2, Article 20.

Simons, A. and vom Brocke, J. (2014). "Enterprise content management in information systems research". vom Brocke, J. and Simons, A. (eds.) Enterprise Content Management in Information Systems Research - Foundations, Methods and Cases. Springer, Heidelberg et al., pp. 3-21.

Smith, H. A. and McKeen, J. D. (2003), "Developments in practice VIII: Enterprise content management", Communications of the Association for Information Systems, 11, pp. 647-659.

Sprehe, J. T. (2005), "The Positive Benefits of Electronic Records Management in the Context of Enterprise Content Management", Government Information Quarterly, 22, pp. 297-303.

Straub, D., Boudreau, M.-C. and Gefen, D. (2004), "Validation guidelines for IS positivist research", Communications of the Association for Information systems, 13, pp. 380-427.

Turner, V., Gantz, J. F., Reinsel, D. and Minton, S. (2014), "The Digital Universe of Opportunities: Rich Data and the Increasing Value of the Internet of Things", available at: http://idcdocserv.com/1678 
(accessed 09. September 2015).

Tyrväinen, P., Päivärinta, T., Salminen, A. and livari, J. (2006), "Characterizing the evolving research on enterprise content management", European Journal of Information Systems, 15, pp. 627-634.

Urbach, N. and Ahlemann, F. (2010), "Structural Equation Modeling in Information Systems Research using Partial Least Squares", Journal of Information Technology Theory and Application, 11, pp. 540.

Urbach, N., Smolnik, S. and Riempp, G. (2009), "The State of Research on Information Systems Success", Business \& Information Systems Engineering, 1, pp. 315-325.

Urbach, N., Smolnik, S. and Riempp, G. (2010), "An Empirical Investigation of Employee Portal Success", The Journal of Strategic Information Systems, 19, pp. 184-206.

Usman, M., Muzaffar, A. W. and Rauf, A. "Enterprise content management (ECM): Needs, challenges and recommendations". 2nd IEEE International Conference on Computer Science and Information Technology (ICCSIT '09), August 8-11, 20092009 Beijing, China. pp. 283-289.

vom Brocke, J., Derungs, R., Herbst, A., Novotny, S. and Simons, A. (2011a), "The drivers behind enterprise content management: a process-oriented perspective", Paper presented at the 19th European Conference on Information Systems (ECIS 2011), Helsinki, Finland.

vom Brocke, J., Simons, A. and Cleven, A. (2011b), "Towards a business process-oriented approach to enterprise content management: The ECM-Blueprinting framework", Information Systems and eBusiness Management, 9, pp. 475-496.

vom Brocke, J., Simons, A., Herbst, A., Derungs, R. and Novotny, S. (2011c), "The business drivers behind ECM initiatives: A process perspective", Business Process Management Journal, 17, pp. 965985.

Wang, Y. S., Wang, H. Y. and Shee, D. Y. (2007), "Measuring E-Learning Systems Success in an Organizational Context: Scale Development and Validation", Computers in Human Behavior, 23, pp. 1792-1808.

Wiltzius, L., Simons, A. and Seidel, S. "A Study on the Acceptance of ECM Systems". 10th International Conference on Wirtschaftsinformatik (WI 2011), 2011 Zurich, Switzerland.

Wong, K. K.-K. (2013), "Partial Least Squares Structural Equation Modeling (PLS-SEM) Techniques Using SmartPLS", Marketing Bulletin, 24. 


\section{Appendix A. Literature}

\section{Table 8. ECM objectives}

\begin{tabular}{|l|l|}
\hline Objectives & References \\
\hline Efficiency & $\begin{array}{l}\text { Andersen (2007), Iverson and Burkart (2007), Dilnutt (2006), Kwok and Chiu (2004), Päivärinta } \\
\text { and Munkvold (2005), Scott et al. (2004), Smith and Mckeen (2003), Sprehe (2005), Vom Brocke } \\
\text { et al. (2011b), Vom Brocke et al. (2011c) }\end{array}$ \\
\hline Collaboration & $\begin{array}{l}\text { Andersen (2007), Iverson and Burkart (2007), Dilnutt (2006), Munkvold et al. (2006), Nordheim } \\
\text { and Päivärinta (2006), Vom Brocke et al. (2011b), Vom Brocke et al. (2011c) }\end{array}$ \\
\hline Compliance & $\begin{array}{l}\text { Andersen (2007), Chiu and Hung (2005), Iverson and Burkart (2007), Dilnutt (2006), Kwok and } \\
\text { Chiu (2004), Munkvold et al. (2006), Nordheim and Päivärinta (2006), Päivärinta and Munkvold } \\
\text { (2005), Vom Brocke et al. (2011b), Vom Brocke et al. (2011c) }\end{array}$ \\
\hline
\end{tabular}

\section{Appendix B. Measures}

The items were measured using a seven-point Likert-scale, using two different parameters: agreement (1 $=$ 'strongly disagree' and $7=$ 'strongly agree' $)$ and frequency $(1=$ 'never' and $7=$ 'very frequently $)$.

C.1. Information quality: (scale type: agreement)

Please assess the quality of the information provided by your organization's ECMS. This includes all available information and documents that support your job.

IQ1: Information and documents provided by our ECMS are relevant to the intended task.

IQ2: Information and documents provided by our ECMS are useful.

IQ3: Information and documents provided by our ECMS are reliable.

IQ4: Information and documents provided by our ECMS are correct.

IQ5: Information and documents provided by our ECMS are up-to-date.

C.2. System quality: (scale type: agreement)

Please assess the quality of your organization's ECMS.

SQ1: Our ECMS is easy to navigate.

SQ2: Our ECMS is easy to use.

SQ3: Our ECMS is user-friendly.

SQ4: Our ECMS enables easy access to information and documents.

SQ5: Our ECMS provides appropriate functionalities for retrieving documents and information.

\section{C.3. Service quality: (scale type: agreement)}

Please assess the service quality of the personnel responsible for supporting the ECMS in your organization.

SE1: The responsible service personnel are always willing to help whenever I need support with our ECMS. 
SE2: The responsible service personnel provide services related to our ECMS at the promised time.

SE3: The responsible service personnel have sufficient knowledge to answer my questions in respect to our ECMS.

SE4: The responsible service personnel are available for consultation about our ECMS.

SE5: The responsible service personnel provide high quality training concerning our ECMS.

\section{C.4. Process quality: (scale type: agreement)}

Please assess the process support of your organization's ECMS.

PQ1: Our ECMS supports the easy initiation of work processes.

PQ2: Our ECMS supports the work processes in a way that allows one to trace them.

PQ3: Our ECMS supports the work processes accurately.

PQ4: Our ECMS supports the work processes reliably.

PQ5: Our ECMS supports the work processes fully.

C.5. Use: (scale type: frequency)

Please indicate how frequently you use the ECMS to perform the following tasks:

UE1: Retrieve information and documents

UE2: Share information and documents

UE3: Edit information and documents

UE4: Delete information and documents

Please answer the following questions concerning your own use of your organization's ECMS.

UE5: How frequently do you use your organization's ECMS?

How many minutes in a typical work day do you spend using your organization's ECMS?

UE6 Minutes per working day (Free input - rescaled to a 1 to 7 scale)

C.6. User Satisfaction: (scale type: agreement)

Please indicate to what degree you agree with each of the following statements regarding your satisfaction with your organization's ECMS.

US1: Our ECMS has met my expectations.

US2: I am satisfied with the effectiveness of our ECMS.

US3: I am satisfied with the efficiency of our ECMS.

US4: I am pleased with the experience of using our ECMS.

US5: Overall, I am satisfied with our ECMS.

C.7. Individual Impact: (scale type: agreement) 
Please assess to what degree you agree with each of the following statements regarding the individual benefits you derive from using your organization's ECMS.

II1: Our ECMS enhances my job efficiency.

II2: Our ECMS enhances my job effectiveness.

II3: Our ECMS improves my job performance.

II4: Our ECMS enables me to accomplish tasks more quickly.

II5: Our ECMS increases my productivity.

C.8. Collaboration: (scale type: agreement)

Please assess the following statements concerning the impact of your organization's ECMS on the collaboration in your organization.

CL1: Our ECMS supports knowledge-sharing within our organization.

CL2: Our ECMS supports a comfortable communication within our organization.

CL3: Our ECMS supports the joint creation of creative information and content.

CL4: Our ECMS helps our organization eliminate the isolated creation of information and documents by functional areas.

C.9. Efficiency: (scale type: agreement)

Please assess the following statements concerning the impact of your organization's ECMS on the efficiency of your organization.

EF1: Our ECMS improves our organization's performance by efficiently reusing existing documents and information.

EF2: Our ECMS enables our organization to use content and information more efficiently.

EF3: Our ECMS supports the organization in publishing documents and content faster.

EF4: Our ECMS helps our organization reduce the search times for documents and information.

C.10. Compliance: (scale type: agreement)

Please assess the following statements concerning the impact of your organization's ECMS on the compliance of your organization.

CP1: Our ECMS enables our organization to manage the deletion of information and documents in accordance with legal and business requirements.

CP2: Our ECMS helps our organization reduce the risk that critical information is stored on local hard drives.

CP3: Our ECMS helps our organization track changes in critical information and documents properly.

CP4: Our ECMS supports our organization in protecting information and documents against unauthorized use.

CP5: Our ECMS enables our organization to record the history of organizational transactions. 


\section{Appendix C. Exploratory Factor Analysis}

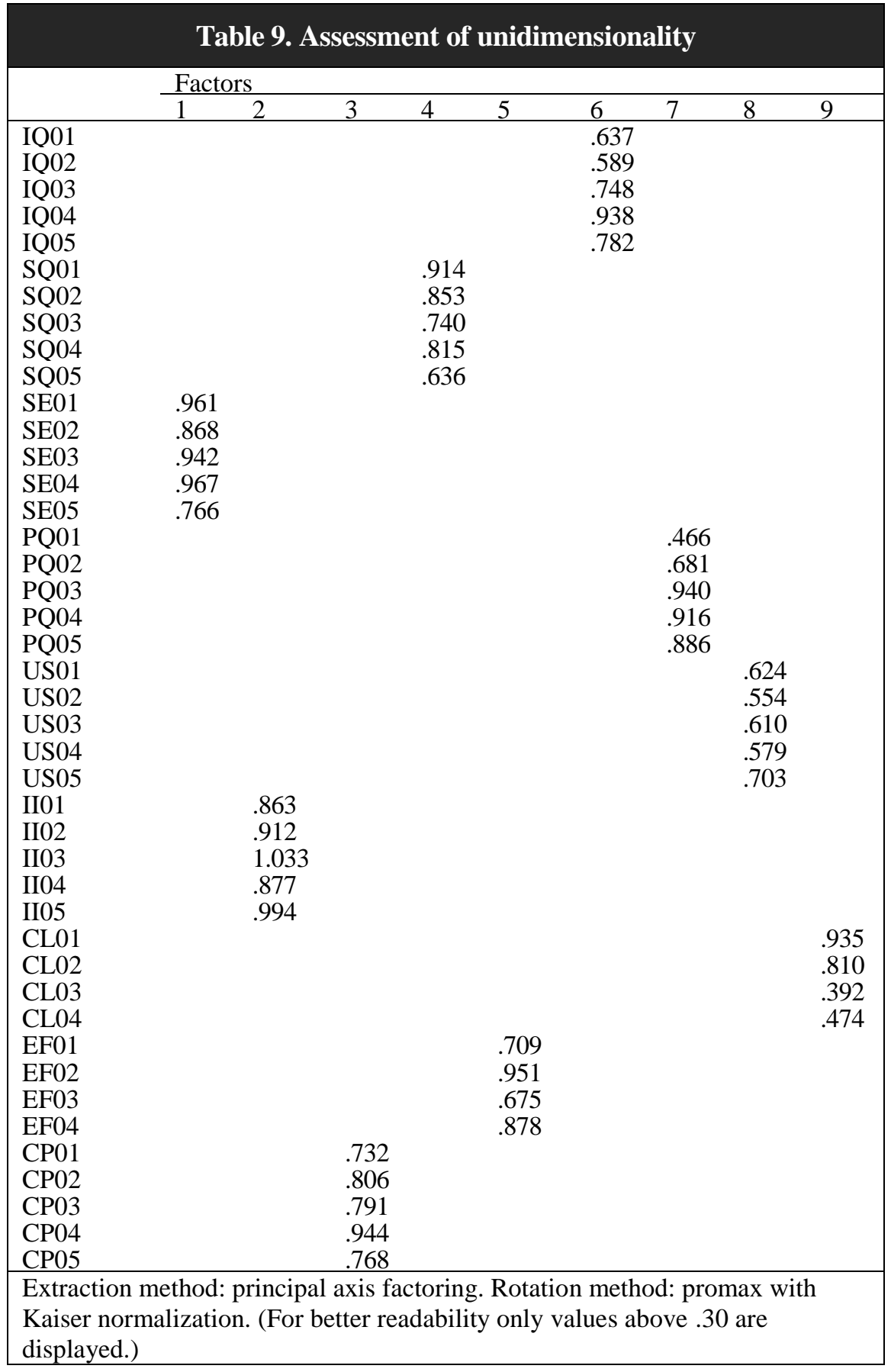




\section{Appendix D. Item Loadings}

\begin{tabular}{|c|c|c|c|}
\hline \multicolumn{4}{|c|}{ Table 10. Indicator reliability } \\
\hline Construct & Item & Loading & t-Value \\
\hline \multirow{4}{*}{ Collaboration } & CL01 & .875 & 58.745 \\
\hline & CL02 & .875 & 48.528 \\
\hline & CL03 & .868 & 49.042 \\
\hline & CL04 & .797 & 25.367 \\
\hline \multirow{5}{*}{ Compliance } & СР01 & .838 & 30.675 \\
\hline & СР02 & .797 & 22.609 \\
\hline & СР03 & .808 & 24.470 \\
\hline & СP04 & .830 & 32.136 \\
\hline & CP05 & .781 & 18.708 \\
\hline \multirow[t]{4}{*}{ Efficiency } & EF01 & .915 & 67.616 \\
\hline & EF02 & .919 & 80.443 \\
\hline & EF03 & .824 & 33.645 \\
\hline & EF04 & .826 & 33.787 \\
\hline \multirow[t]{5}{*}{ Individual impact } & II01 & .943 & 112.947 \\
\hline & II02 & .946 & 105.457 \\
\hline & II03 & .952 & 101.808 \\
\hline & II04 & .928 & 61.916 \\
\hline & II05 & .964 & 170.724 \\
\hline \multirow[t]{5}{*}{ Information quality } & IQ01 & .798 & 25.453 \\
\hline & IQ02 & .852 & 31.878 \\
\hline & IQ03 & .848 & 32.117 \\
\hline & IQ04 & .845 & 30.928 \\
\hline & IQ05 & .761 & 22.601 \\
\hline \multirow[t]{5}{*}{ Process quality } & PQ01 & .864 & 42.920 \\
\hline & $\mathrm{PQ} 02$ & .877 & 41.385 \\
\hline & PQ03 & .926 & 79.932 \\
\hline & PQ04 & .931 & 83.364 \\
\hline & PQ5 & .878 & 43.048 \\
\hline \multirow{5}{*}{ Service quality } & SE01 & .923 & 82.910 \\
\hline & SE02 & .898 & 55.500 \\
\hline & SE03 & .915 & 75.551 \\
\hline & SE04 & .901 & 46.050 \\
\hline & SE05 & .810 & 26.005 \\
\hline \multirow{5}{*}{ System quality } & SQ01 & .921 & 94.565 \\
\hline & SQ02 & .907 & 50.733 \\
\hline & SQ03 & .908 & 67.862 \\
\hline & SQ04 & .867 & 55.695 \\
\hline & SQ05 & .811 & 30.694 \\
\hline \multirow{5}{*}{ User satisfaction } & US01 & .915 & 62.371 \\
\hline & US02 & .912 & 68.717 \\
\hline & US03 & .909 & 65.444 \\
\hline & US04 & .936 & 90.003 \\
\hline & US05 & .954 & 145.283 \\
\hline
\end{tabular}




\section{Appendix E. Cross Loadings}

\begin{tabular}{|c|c|c|c|c|c|c|c|c|c|}
\hline & CL & $\mathbf{C P}$ & EF & II & IQ & PQ & SE & SQ & US \\
\hline CL01 & .875 & .326 & .600 & .585 & .303 & .535 & .364 & .447 & .583 \\
\hline CL02 & .875 & .344 & .681 & .609 & .348 & .556 & .424 & .485 & .638 \\
\hline CL03 & .868 & .452 & .626 & .602 & .378 & .599 & .370 & .516 & .597 \\
\hline CL04 & .797 & .508 & .666 & .565 & .349 & .531 & .354 & .473 & .618 \\
\hline CP01 & .344 & .838 & .427 & .303 & .126 & .377 & .206 & .252 & .321 \\
\hline СР02 & .442 & .797 & .498 & .380 & .220 & .373 & .233 & .330 & .411 \\
\hline CP03 & .396 & .808 & .499 & .326 & .275 & .381 & .199 & .353 & .361 \\
\hline CP04 & .383 & .830 & .492 & .338 & .234 & .403 & .198 & .329 & .385 \\
\hline СР05 & .346 & .781 & .449 & .302 & .126 & .334 & .130 & .248 & .249 \\
\hline EF01 & .700 & .552 & .915 & .661 & .449 & .618 & .367 & .574 & .692 \\
\hline EF02 & .688 & .473 & .919 & .659 & .430 & .583 & .366 & .584 & .682 \\
\hline EF03 & .650 & .477 & .824 & .596 & .324 & .550 & .357 & .547 & .598 \\
\hline EF04 & .582 & .549 & .826 & .553 & .313 & .543 & .317 & .543 & .591 \\
\hline II01 & .665 & .402 & .694 & .943 & .391 & .652 & .264 & .620 & .758 \\
\hline II02 & .681 & .380 & .679 & .946 & .435 & .629 & .278 & .606 & .757 \\
\hline II03 & .624 & .413 & .645 & .952 & .461 & .652 & .262 & .576 & .698 \\
\hline II04 & .633 & .355 & .662 & .928 & .411 & .612 & .316 & .635 & .734 \\
\hline IIO5 & .666 & .390 & .679 & .964 & .437 & .643 & .321 & .618 & .742 \\
\hline IQ01 & .299 & .177 & .309 & .399 & .800 & .315 & .264 & .439 & .354 \\
\hline IQ02 & .334 & .227 & .315 & .424 & .853 & .361 & .279 & .430 & .348 \\
\hline IQ03 & .337 & .201 & .389 & .361 & .847 & .372 & .306 & .422 & .376 \\
\hline IQ04 & .288 & .196 & .360 & .299 & .844 & .311 & .316 & .366 & .312 \\
\hline IQ05 & .391 & .206 & .432 & .350 & .761 & .381 & .287 & .376 & .362 \\
\hline PQ01 & .606 & .381 & .552 & .619 & .320 & .863 & .451 & .565 & .607 \\
\hline PQ02 & .576 & .439 & .569 & .578 & .383 & .877 & .405 & .550 & .575 \\
\hline PQ03 & .586 & .424 & .634 & .630 & .414 & .926 & .423 & .514 & .606 \\
\hline PQ04 & .563 & .398 & .610 & .598 & .421 & .931 & .436 & .527 & .610 \\
\hline PQ05 & .580 & .428 & .582 & .587 & .368 & .878 & .450 & .483 & .570 \\
\hline SE01 & .402 & .210 & .388 & .297 & .324 & .459 & .923 & .365 & .436 \\
\hline SE02 & .390 & .165 & .333 & .245 & .284 & .395 & .898 & .300 & .381 \\
\hline SE03 & .416 & .212 & .372 & .259 & .322 & .436 & .915 & .342 & .412 \\
\hline SE04 & .361 & .222 & .360 & .270 & .338 & .442 & .901 & .354 & .379 \\
\hline SE05 & .405 & .268 & .342 & .282 & .299 & .417 & .811 & .300 & .337 \\
\hline SQ01 & .502 & .341 & .561 & .598 & .429 & .549 & .392 & .921 & .705 \\
\hline SQ02 & .475 & .316 & .522 & .539 & .452 & .510 & .347 & .908 & .671 \\
\hline SQ03 & .503 & .302 & .560 & .560 & .389 & .527 & .363 & .908 & .678 \\
\hline SQ04 & .518 & .322 & .598 & .583 & .478 & .515 & .296 & .867 & .668 \\
\hline SQ05 & .486 & .385 & .610 & .573 & .454 & .505 & .252 & .811 & .633 \\
\hline US01 & .640 & .347 & .629 & .680 & .376 & .572 & .427 & .677 & .915 \\
\hline US02 & .654 & .416 & .694 & .743 & .440 & .627 & .390 & .657 & .912 \\
\hline US03 & .659 & .396 & .695 & .713 & .325 & .637 & .362 & .698 & .909 \\
\hline US04 & .656 & .432 & .698 & .739 & .443 & .611 & .416 & .748 & .936 \\
\hline US05 & .690 & .402 & .691 & .732 & .397 & .622 & .435 & .733 & .954 \\
\hline
\end{tabular}




\section{Appendix F. Formative Constructs}

\begin{tabular}{|llll|}
\hline \multicolumn{4}{|c|}{ Table 12. Assessment of formative construct use } \\
\hline & Weight & t-value & VIF \\
\hline UE01 & .173 & 1.244 & 1.163 \\
UE02 & .800 & 7.251 & 1.208 \\
UE03 & -.199 & 1.428 & 1.379 \\
UE04 & .351 & 3.088 & 1.130 \\
UE05 & -.086 & 0.558 & 1.250 \\
UE06 & .210 & 1.731 & 1.175 \\
\hline
\end{tabular}

\section{Appendix G. Interconstruct Correlations}

\begin{tabular}{|c|c|c|c|c|c|c|c|c|c|}
\hline & CL & $\mathrm{CP}$ & EF & II & IQ & $P Q$ & SE & SQ & US \\
\hline CL & 1.000 & & & & & & & & \\
\hline $\mathrm{CP}$ & .475 & 1.000 & & & & & & & \\
\hline $\mathrm{EF}$ & .753 & .586 & 1.000 & & & & & & \\
\hline II & .692 & .410 & .710 & 1.000 & & & & & \\
\hline IQ & .403 & .246 & .439 & .450 & 1.000 & & & & \\
\hline $\mathrm{PQ}$ & .651 & .462 & .658 & .674 & .425 & 1.000 & & & \\
\hline SE & .443 & .241 & .404 & .304 & .353 & .484 & 1.000 & & \\
\hline SQ & .562 & .376 & .645 & .646 & .498 & .590 & .375 & 1.000 & \\
\hline US & .713 & .432 & .737 & .780 & .429 & .664 & .439 & .760 & 1.000 \\
\hline
\end{tabular}

\section{Appendix H. Path Coefficients}

\begin{tabular}{|c|c|c|c|c|c|}
\hline \multicolumn{2}{|c|}{ Hypothesis } & $\beta(A)$ & t-Value (A) & $\beta(B)$ & $\mathrm{t}-\mathrm{Value}(\mathrm{B})$ \\
\hline $\mathrm{H} 1$ & System quality $\rightarrow$ use & .134 & 1.637 & -.049 & 0.515 \\
\hline $\mathrm{H} 2$ & System quality $\rightarrow$ user satisfaction & .535 & 9.978 & .555 & 10.646 \\
\hline $\mathrm{H} 3$ & Service quality $\rightarrow$ use & -.015 & 0.209 & -.048 & 0.708 \\
\hline $\mathrm{H} 4$ & Service quality $\rightarrow$ user satisfaction & .092 & 1.892 & .090 & 1.804 \\
\hline H5 & Information quality $\rightarrow$ use & .173 & 2.221 & .181 & 2.367 \\
\hline H6 & Information quality $\rightarrow$ user satisfaction & -.030 & .458 & -.005 & .077 \\
\hline $\mathrm{H7}$ & Process quality $\rightarrow$ use & .264 & 3.575 & .164 & 1.985 \\
\hline H8 & Process quality $\rightarrow$ user satisfaction & .257 & 4.306 & .295 & 4.899 \\
\hline H9 & Use $\rightarrow$ user satisfaction & .143 & 3.212 & $\mathrm{n} / \mathrm{a}$ & $\mathrm{n} / \mathrm{a}$ \\
\hline H10 & User satisfaction $\rightarrow$ use & $\mathrm{n} / \mathrm{a}$ & $\mathrm{n} / \mathrm{a}$ & .326 & 3.419 \\
\hline H11 & Use $\rightarrow$ individual impact & .260 & 5.348 & .264 & 5.686 \\
\hline H12 & User satisfaction $\rightarrow$ individual impact & .661 & 15.586 & .660 & 15.967 \\
\hline H13 & Individual impact $\rightarrow$ efficiency & .294 & 3.322 & .292 & 3.317 \\
\hline H14 & Individual impact $\rightarrow$ collaboration & .295 & 3.975 & .294 & 3.885 \\
\hline H15 & Individual impact $\rightarrow$ compliance & .163 & 1.446 & .159 & 1.431 \\
\hline H16 & Use $\rightarrow$ efficiency & .097 & 1.505 & .099 & 1.556 \\
\hline H17 & Use $\rightarrow$ collaboration & .094 & 1.551 & .094 & 1.524 \\
\hline $\mathrm{H} 18$ & Use $\rightarrow$ compliance & .036 & .438 & .042 & .517 \\
\hline H19 & User satisfaction $\rightarrow$ efficiency & .464 & 6.223 & .465 & 6.253 \\
\hline $\mathrm{H} 20$ & User satisfaction $\rightarrow$ collaboration & .441 & 6.914 & .442 & 6.897 \\
\hline $\mathrm{H} 21$ & User satisfaction $\rightarrow$ compliance & .291 & 2.705 & .292 & 2.762 \\
\hline
\end{tabular}




\section{Appendix I. Index Value and Standard Deviation}

\begin{tabular}{|lrr|}
\hline \multicolumn{3}{|c|}{ Table 15. Index values and STD } \\
\hline \multicolumn{3}{|c|}{ Index Value } \\
\hline Collaboration & 4.471 & 1.526 \\
Compliance & 4.325 & 1.278 \\
Efficiency & 4.483 & 1.393 \\
Individual impact & 4.137 & 1.604 \\
Information quality & 5.296 & 1.108 \\
Process quality & 4.372 & 1.388 \\
Service quality & 4.963 & 1.357 \\
System quality & 4.239 & 1.542 \\
Use & 4.240 & 1.204 \\
User satisfaction & 4.233 & 1.457 \\
\hline
\end{tabular}

